\title{
Risk Factors for Repeat Abdominal Surgery in Korean Patients with Crohn's Disease: A Multi-Center Study of a Korean Inflammatory Bowel Disease Study Group
}

\author{
Kil Yeon Lee, Chang Sik Yu ${ }^{1}$, Kang Young Lee ${ }^{2}$, Yong Beom Cho ${ }^{3}$, Kyu Joo Park ${ }^{4}$, Gyu-Seog Choi ${ }^{5}$, \\ Sang Nam Yoon ${ }^{6}$, Hanna Yoo ${ }^{7}$; IBD Study Group, Korean Society of Coloproctology \\ Department of Surgery, Kyung Hee University School of Medicine, Seoul; ${ }^{1}$ Department of Colon and Rectal Surgery, Asan Medical Center, \\ University of Ulsan College of Medicine, Seoul; ${ }^{2}$ Department of Surgery, Yonsei University College of Medicine, Seoul; ${ }^{3}$ Department of \\ Surgery, Samsung Medical Center, Sungkyunkwan University School of Medicine, Seoul; ${ }^{4}$ Department of Surgery, Seoul National University \\ College of Medicine, Seoul; ${ }^{5}$ Department of Surgery, Kyungpook National University School of Medicine, Daegu; ${ }^{6}$ Department of Surgery, \\ Hansol Hospital, Seoul; ${ }^{7}$ Department of Statistics, College of Political Science and Economics, Korea University, Seoul, Korea
}

Purpose: The purpose of this study was to assess the risk factors for repeated abdominal surgery in Crohn's disease (CD) patients after the first abdominal surgery. Prior studies have tried to identify the risk factors for postoperative recurrence in CD patients, but the results of the studies have been inconsistent. Furthermore, few data on the risk factors for repeated abdominal surgery are available.

Methods: Clinical data on CD patients who underwent abdominal surgery from January 2000 to December 2009 were collected from seventeen university hospitals and one colorectal clinic. Data from a total of 708 patients were analyzed to find the risk factors for repeated abdominal surgery in CD patients. The mean follow-up period was 72 months.

Results: The risk of repeated abdominal surgery was 3 times higher in young patients (below 16 years old) than in older patients (odds ratio [OR], 3.056; 95\% confidence interval [CI], 1.021 to 9.150); $\mathrm{P}=0.046$ ). Stricturing behavior at diagnosis was also a risk factor for repeated abdominal surgery $(\mathrm{OR}, 2.438 ; 95 \% \mathrm{CI}, 1.144$ to 5.196; $\mathrm{P}=0.021)$. Among operative indications, only intra-abdominal abscess was associated with repeated abdominal surgery (OR, 2.393; 95\% CI, 1.098 to 5.216; $\mathrm{P}=0.028)$. Concerning type of operation, an ileostomy might be a risk factor for repeated abdominal surgery (OR, 11.437; 95\% CI, 1.451 to $90.124 ; \mathrm{P}=0.021)$. Emergency surgery $(\mathrm{OR}, 4.994 ; 95 \% \mathrm{CI}, 2.123$ to $11.745 ; \mathrm{P}<0.001)$ and delayed diagnosis after surgery $(\mathrm{OR}, 2.339 ; 95 \% \mathrm{CI}, 1.147$ to $4.771 ; \mathrm{P}=0.019)$ also increased the risk of repeated abdominal surgery. Conclusion: Young age (below 16 years), stricturing behavior, intra-abdominal abscess, emergency surgery, and delayed diagnosis after surgery were identified as possible risk factors for repeated abdominal surgery in CD patients.

Keywords: Crohn's disease; Recurrence; Surgery

\section{INTRODUCTION}

Crohn's disease (CD) is heterogeneous in nature; consequently, its

Received: June 2, 2012 - Accepted: August 3, 2012

Correspondence to: Chang Sik Yu, M.D.

Department of Colon and Rectal Surgery, Asan Medical Center, University of Ulsan College of Medicine, 88 Olympic-ro 43-gil, Songpa-gu, Seoul

138-736, Korea

Tel: +82-2-3101-3494, Fax: +82-2-3101-6701

E-mail: csyu@amc.seoul.kr

(c) 2012 The Korean Society of Coloproctology

This is an open-access article distributed under the terms of the Creative Commons Attribution NonCommercial License (http://creativecommons.org/licenses/by-nc/3.0) which permits unrestricted noncommercial use, distribution, and reproduction in any medium, provided the original work is properly cited. clinical course is relatively unpredictable. The only consistent factor in CD is its inconsistency [1]. Some patients have a relatively mild form, but others experience a severe form of $\mathrm{CD}$ requiring surgery or have postoperative recurrence. Over $80 \%$ of CD patients will undergo surgery, and approximately one-third of those patients will require reoperation [2]. Reported reoperation rates range from 20 to $25 \%$ at 5 years after resection and 34 to $39 \%$ at 10 years $[3,4]$. Several studies have reported the risk factors of an initial intestinal resection or recurrence after the primary operation. Different studies have revealed numerous risk factors for postoperative recurrences, but the results are often not comparable because of differing patient populations and clinical manifestations $[5,6]$. In addition, no consistent risk factors for surgery or 
recurrence, except smoking, have been identified [7, 8]. Furthermore, few studies have evaluated the risk factors for reoperation after the primary surgery in CD patients. Therefore, the aim of the present study was to evaluate the probability of reoperation and to assess the risk factors for reoperation after the primary surgery for CD.

\section{METHODS}

\section{Data management}

The data for biopsy-proven CD patients who underwent abdominal surgery from January 2000 to December 2009 were collected retrospectively. The operations were performed at 18 different hospitals (17 university hospitals and one colorectal clinic). The factors included in the study protocol were decided at a meeting held before data collection. The data of 754 patients were collected initially, and 46 cases were excluded because of data duplication or unmet criteria (Fig. 1). Data from a total of $708 \mathrm{CD}$ patients were analyzed to determine the risk factors for repeated abdominal surgery. The mean follow-up period was 72 months. The variables that were analyzed were gender, family history, age at diagnosis, disease behavior at diagnosis, and disease location at diagnosis ac-

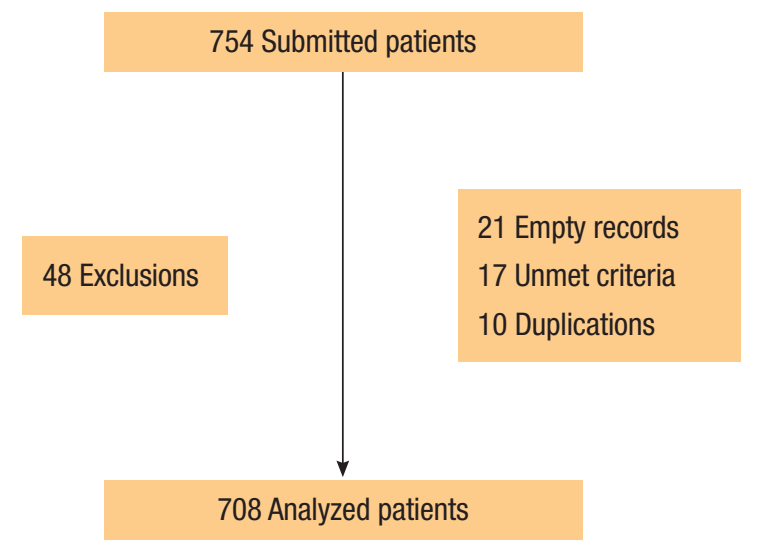

Fig. 1. Study selection flow chart. cording to the Montreal classification. Other variables were indications, type of first abdominal surgery, and the time interval between diagnosis and surgery.

\section{Statistical analysis}

For the continuous variables, normality was tested first. When the normality assumption was satisfied, a one-way analysis of variance was used; otherwise, a Kruskal-Wallis test was utilized to test whether a mean difference between the number of operations existed $(1,2, \geq 3)$. In addition, for the categorical variables, a Pearson chi-square test or a Fisher's exact test was used as appropriate to evaluate the association between the number of operations $(1,2$, $\geq 3$ ). In order to evaluate the relationships between the number of operations and the risk factors, we used univariate and multivariate logistic regression modeling. Since the percentage of patients who had more than three operations was only $6.2 \%$, the number of the operations was divided into two categories $(1, \geq 2)$. Additionally, within the independent variables of surgery type, indication for surgery and main symptoms, a few categories had a low percentage of patients; thus, for the stability of the analysis, those categories were eliminated/merged. For the goodness-of-fit, Hosmer-Leme show statistics were utilized, and the area under the receiver operating characteristic curve was used to assess the model discrimination. All statistical analyses were performed using SPSS ver. 15.0 (SPSS Inc., Chicago, IL, USA).

\section{RESULTS}

Twenty-four percent of the CD patients with primary abdominal surgery experienced repeated abdominal surgery, and $25 \%$ of that $24 \%$ underwent one additional abdominal surgery. The male-tofemale ratio of the CD patients with abdominal surgery was 2.27:1, and the mean ages of male and female patients were 34.0 and 34.16 years, respectively (Table 1). Family history was confirmed in only $2.2 \%$ of the patients. Gender and family history were not associated with repeated abdominal surgery in CD patients. All patients were classified according to the Montreal classification (Table 2). Patients between 17 and 40 years of age (A2), ileal location (L1),

Table 1. Baseline population characteristics

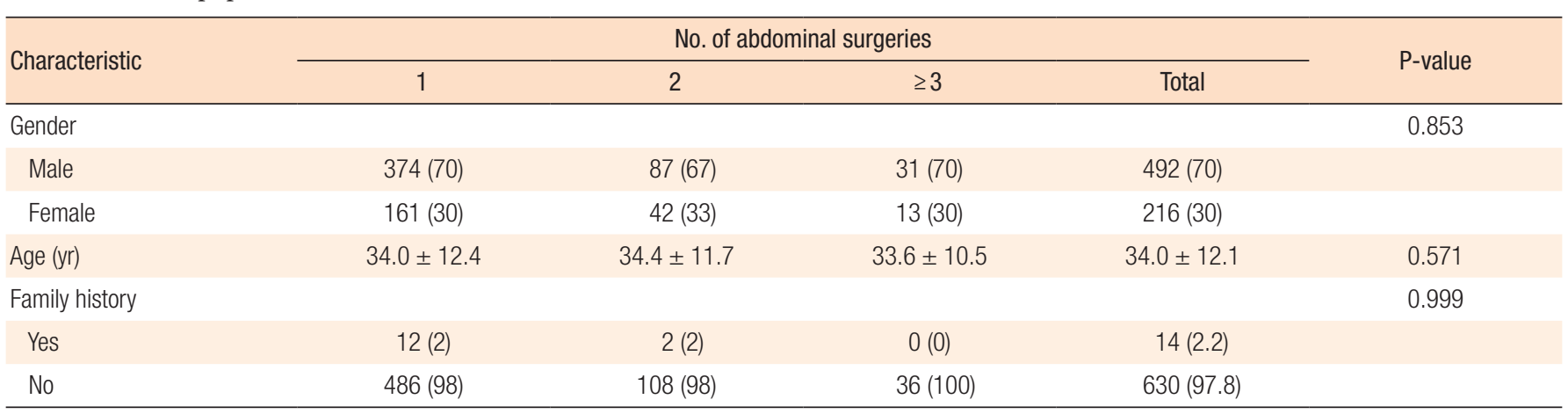

Values are presented as number (\%) or mean \pm SD. 
and stricturing behavior (B2) were the most common subgroups in the CD patients who underwent primary abdominal surgery

Table 2. Montreal classification of Crohn's disease

\begin{tabular}{l}
\hline Age at diagnosis (yr) \\
A1 ( $\leq 16)$ \\
A2 (17-40) \\
A3 ( $\geq 41)$ \\
Location \\
L1 (ileal) \\
L2 (colonic) \\
L3 (ileocolonic) \\
L4 (isolated upper disease $\left.{ }^{a}\right)$ \\
Behavior \\
B1 (non-stricturing, non-penetrating) \\
B2 (stricturing) \\
B3 (penetrating) \\
p (perianal disease modifier) \\
\hline
\end{tabular}

a $\mathrm{L} 4$ is a modifier that can be added to L1-L3 when concomitant upper gastrointestinal disease is present. ${ }^{\mathrm{b}} \mathrm{p}$ is added to B1-B3 when concomitant perianal disease is present.
(Table 3). Medical intractability (21.5\%), intestinal obstruction (24.2\%), intra-abdominal abscess (23.4\%), and enterocutaneous fistula (18.5\%) were common causes of primary abdominal surgery. Intestinal obstruction (31.5\%) and intra-abdominal abscess (33.1\%) were also common causes of repeated abdominal surgery (Table 4). Small bowel segmental resection (28.2\%) was the most common procedure performed in the first abdominal surgery. Of the total number of first abdominal surgeries for CD patients, a right colectomy and an ileocecectomy were performed in $26.7 \%$ and $25.0 \%$ of the patients, respectively (Table 5).

Table 6 summarizes the results of the univariate and the multivariate analyses. The risk of repeated abdominal surgery was approximately three times higher in young patients (under the age of 16 years) than in older patients (odds ratio [OR], 3.056; 95\% confidence interval [CI], 1.021 to $9.150 ; \mathrm{P}=0.046$ ). Stricturing behavior was a greater risk factor for repeated abdominal surgery (OR, 2.438; 95\% CI, 1.144 to 5.196; $\mathrm{P}=0.021$ ) than was penetrating behavior or non-stricturing and non-penetrating behavior. However, the number of surgeries was not influenced by the location of the disease at diagnosis. Intractability, obstruction, abscess and fistula were the main causes of surgery, and only abscess was associated with repeat surgery (OR, 2.393; 95\% CI, 1.098 to 5.216; $\mathrm{P}=0.028$ ). Concerning the type of surgery, an ileostomy may be a risk factor for repeat abdominal surgery (OR, 11.437; 95\% CI,

Table 3. Allocation of patients to the 36 subgroups of the Montreal classification

\begin{tabular}{|c|c|c|c|c|c|c|c|c|c|c|}
\hline & \multicolumn{3}{|c|}{$\mathrm{A} 1$} & \multicolumn{3}{|c|}{ A2 } & \multicolumn{3}{|c|}{ A3 } & \multirow{2}{*}{ Total } \\
\hline & B1 & B2 & B3 & B1 & B2 & B3 & $\mathrm{B} 1$ & B2 & B3 & \\
\hline L1 & 1.4 & 1.2 & 0.3 & 5.2 & 14.7 & 11.1 & 1.7 & 2.8 & 2.8 & 41.2 \\
\hline L2 & 0.6 & 0.6 & 0.2 & 4.8 & 5.1 & 3.1 & 1.4 & 0.8 & 0.5 & 16.9 \\
\hline L3 & 1.5 & 2.3 & 0.6 & 6.5 & 11.8 & 10.9 & 1.5 & 1.8 & 0.6 & 37.6 \\
\hline L4 & 0.0 & 0.2 & 0.3 & 0.6 & 1.5 & 0.9 & 0.2 & 0.2 & 0.5 & 4.3 \\
\hline Total & 3.5 & 4.3 & 1.4 & 17.1 & 33.2 & 26.0 & 4.8 & 5.5 & 4.3 & 100.0 \\
\hline
\end{tabular}

Values are presented as percentage.

A, age at diagnosis; A1, $\leq 16$ yr; A2, 17-40 yr; A3, $\geq 41$ yr; B, behavior; B1, non-stricturing, non-penetrating; B2, structuring; B3, penetrating; L, location; L1, ileal; L2, coIonic; $L 3$, ileocolonic; $L 4$, isolated upper disease.

Table 4. Causes of abdominal surgery in Crohn's disease patients

\begin{tabular}{|c|c|c|c|c|}
\hline \multirow{2}{*}{ Cause } & \multicolumn{3}{|c|}{ No. of abdominal surgeries } & \multirow{2}{*}{ Total } \\
\hline & 1 & 2 & $\geq 3$ & \\
\hline Intractability & $113(21.5)$ & $6(4.8)$ & $4(10.3)$ & $123(17.9)$ \\
\hline Intestinal obstruction & $127(24.2)$ & $39(31.5)$ & $11(28.2)$ & $177(25.7)$ \\
\hline Intra-abdominal abscess & $123(23.4)$ & $41(33.1)$ & $10(25.6)$ & $174(25.3)$ \\
\hline Enterocutaneous fistula & $97(18.5)$ & $14(11.3)$ & $4(10.3)$ & $115(16.7)$ \\
\hline Fulminant colitis & $5(1.0)$ & $0(0)$ & $0(0)$ & $5(0.7)$ \\
\hline Massive bleeding & $7(1.3)$ & $6(4.8)$ & $0(0)$ & $13(1.9)$ \\
\hline Others & $53(10.1)$ & $18(14.5)$ & $10(25.6)$ & $81(11.8)$ \\
\hline
\end{tabular}

Values are presented as number (\%). 
Table 5. Types of abdominal surgery in Crohn's disease patients

\begin{tabular}{|c|c|c|c|c|}
\hline \multirow{2}{*}{ Type of surgery } & \multicolumn{3}{|c|}{ No. of abdominal surgeries } & \multirow{2}{*}{ Total } \\
\hline & 1 & 2 & $\geq 3$ & \\
\hline Strictureplasty only & $3(0.6)$ & $0(0)$ & $2(4.8)$ & $5(0.7)$ \\
\hline lleocecectomy & $130(25.0)$ & $28(21.7)$ & $8(19.0)$ & $166(24.0)$ \\
\hline Right colectomy & $139(26.7)$ & $23(17.8)$ & $3(7.1)$ & $165(23.8)$ \\
\hline Total colectomy & $33(6.3)$ & $2(1.6)$ & $2(4.8)$ & $37(5.3)$ \\
\hline Total proctocolectomy with ileal pouch anal anastomosis & $0(0)$ & $2(1.6)$ & $1(2.4)$ & $3(0.4)$ \\
\hline Total proctocolectomy with permanent ileostomy & $23(4.4)$ & $2(1.6)$ & $0(0)$ & $25(3.6)$ \\
\hline lleostomy only & $3(0.6)$ & $9(7.0)$ & $0(0)$ & $12(1.7)$ \\
\hline Others & $36(6.9)$ & $9(7.0)$ & $9(21.4)$ & $54(7.8)$ \\
\hline
\end{tabular}

Values are presented as number (\%).

1.451 to $90.124 ; \mathrm{P}=0.021)$. Emergency surgery (OR, 4.994; 95\% $\mathrm{CI}, 2.123$ to $11.745 ; \mathrm{P}<0.001)$ and delayed diagnosis after surgery (OR, 2.339; 95\% CI, 1.147 to 4.771; $\mathrm{P}=0.019$ ) increased the risk for repeat abdominal surgery.

\section{DISCUSSION}

According to the European consensus on definitions and diagnosis of $\mathrm{CD}$, recurrence is primarily used to define the reappearance of lesions after surgical resection while relapse refers to the reappearance of symptoms [9]. Recurrence is the main problem during the treatment of $\mathrm{CD}$. Knowing the risk factors for recurrence would be helpful in managing CD not only for physicians but also for patients. However, due to the heterogeneous nature of $\mathrm{CD}$, the reported risk factors for recurrence after abdominal surgery for CD patients have been inconsistent, so clarifying the risk factors for repeated abdominal surgery in CD patients is difficult. The recurrence rate varies according to the diagnostic method, follow-up duration and ethnicity.

Despite the obvious limitation of using age at diagnosis as a surrogate marker of disease onset, it is nevertheless an attractive, readily available, and stable criterion for distinguishing different disease patterns at diagnosis [10]. With respect to age of onset, the Montreal classification allows for early onset of disease to be categorized separately as a new A1 category for patients with a diagnosis age of 16 years or younger whereas A2 and A3 account for diagnosis ages of 17 to 40 years and of over 40 years, respectively [11]. This change reflects many studies that have reported that specific serotypes or genotypes are more frequently found in early onset CD [12-15]. Early onset CD is usually more severe than A2 or A3 onset. Thia et al. [10] observed that young patients had a tendency toward recurrent clinical flares, indicating a more active disease, and were more likely to receive immunosuppressive therapy than older patients. Polito et al. [16] observed that compared to an older age at diagnosis, defined as individuals older than 40 years of age, a younger age at diagnosis, defined as individuals under 20 years of age, was associated with greater small bowel involvement, more severe stricturing disease, and a higher surgical rate. These results are consistent with the results from the present study. A young age, less than 16 years, was a risk factor for repeated abdominal surgery in $\mathrm{CD}$ patients.

Several studies have reviewed early disease onset or diagnosis among CD patients with a family history $[16,17]$. Polito et al. [16] postulated that the role of genetic anticipation with greater contribution of maladaptive genes led to an earlier onset of disease manifestation and greater severity in patients with a positive family history. Given that only $2 \%$ of the patients in the present study had a positive family history, other reasons may account for young patients experiencing a more severe clinical course than older patients in the present study cohort [10].

Non-stricturing, non-penetrating, stricturing, and penetrating disease behaviors are the main categories in the classification of CD patients. The present study revealed that stricturing disease behavior was associated with repeated abdominal surgery in CD patients. This result is significantly different from other reports. In other studies, penetrating behavior was a risk factor for postsurgical recurrence [8, 18-20]. However, Khoury et al. [21] reported that stricturing behavior was a risk factor for early reoperation. Concerning disease location, several studies demonstrated that the risk of recurrence was highest in ileocolonic $\mathrm{CD}$ and lowest in colonic CD [22-24]. In the present study, disease location was not a risk factor for repeat abdominal surgery in CD patients. The influences of disease location and disease behavior on the postoperative recurrence of CD are unclear because these clinical characteristics have been observed to change over time [25].

Among the surgical procedures performed in the first abdominal surgery, only the ileostomy increased the risk for repeated abdominal surgery in CD patients. Because the diseased bowel was 


\section{Coloproctology Kil Yeon Lee, et al.}

Table 6. Univariate and multivariate analyses of risk factors for repeat abdominal surgery in Crohn's disease patients

\begin{tabular}{|c|c|c|c|c|c|c|c|}
\hline & & & & 1 time & times & & \\
\hline & No. & & Univaria & analysis & & Multivarie & analysis \\
\hline & & $\beta$ & P-value & $\mathrm{OR}(95 \% \mathrm{Cl})$ & $\beta$ & P-value & OR $(95 \% \mathrm{Cl})$ \\
\hline Gender & & & & & & & \\
\hline Male & 492 & 0.014 & 0.948 & $1.014(0.671-1.532)$ & 0.041 & 0.889 & $1.042(0.585-1.858)$ \\
\hline Female & 216 & 0 & - & & 0 & - & \\
\hline Family history & & & & & & & \\
\hline Yes & 11 & -0.205 & 0.795 & $0.815(0.174-3.820)$ & 0.587 & 0.519 & $1.798(0.302-10.694)$ \\
\hline No & 574 & 0 & - & & 0 & - & \\
\hline Age at diagnosis (yr) & & & & & & & \\
\hline$\leq 16$ & 57 & 0.321 & 0.450 & $1.379(0.599-3.171)$ & 1.117 & 0.046 & $3.056(1.021-9.150)$ \\
\hline $17-40$ & 483 & 0.354 & 0.244 & $1.425(0.785-2.587)$ & 0.540 & 0.167 & 1.717 (0.797-3.696) \\
\hline$\geq 41$ & 85 & 0 & - & & 0 & - & \\
\hline Location & & & & & & & \\
\hline lleal & 239 & 0.147 & 0.759 & $1.159(0.451-2.974)$ & -0.273 & 0.652 & $0.761(0.232-2.495)$ \\
\hline Colonic & 90 & 0.299 & 0.563 & $1.348(0.490-3.710)$ & 0.312 & 0.669 & $1.366(0.328-5.688)$ \\
\hline Ileocolonic & 230 & 0.221 & 0.645 & $1.248(0.486-3.202)$ & 0.354 & 0.582 & $1.425(0.404-5.028)$ \\
\hline Isolated upper disease & 31 & 0 & - & & 0 & - & \\
\hline Behavior & & & & & & & \\
\hline Non-stricturing, non-penetrating & 140 & 0.035 & 0.902 & $1.035(0.595-1.803)$ & 0.058 & 0.885 & $1.060(0.483-2.324)$ \\
\hline Stricturing & 251 & 0.496 & 0.033 & $1.643(1.041-2.593)$ & 0.891 & 0.021 & $2.438(1.144-5.196)$ \\
\hline Penetrating & 192 & 0 & - & & 0 & - & \\
\hline Type of surgery & & & & & & & \\
\hline Strictureplasty & 5 & 1.083 & 0.248 & $2.952(0.471-18.508)$ & 1.025 & 0.383 & $2.788(0.278-27.949)$ \\
\hline Small bowel resection & 199 & 0.648 & 0.013 & $1.912(1.148-3.183)$ & 0.333 & 0.352 & $1.395(0.692-2.811)$ \\
\hline Right colectomy & 156 & -0.267 & 0.386 & $0.766(0.419-1.400)$ & -0.807 & 0.050 & $0.446(0.199-1.000)$ \\
\hline Left colectomy & 8 & -0.458 & 0.674 & $0.633(0.075-5.351)$ & -1.125 & 0.357 & $0.325(0.030-3.558)$ \\
\hline Total colectomy & 35 & -0.879 & 0.169 & $0.415(0.119-1.453)$ & -0.725 & 0.438 & $0.485(0.078-3.028)$ \\
\hline Total proctocolectomy with IPAA & 20 & -0.709 & 0.360 & $0.492(0.108-2.244)$ & -1.191 & 0.284 & 0.304 (0.304-2.682) \\
\hline lleostomy only & 10 & 2.874 & $<0.001$ & $17.714(3.566-87.989)$ & 2.437 & 0.021 & $11.437(1.451-90.124)$ \\
\hline Others & 43 & 0.760 & 0.050 & $2.138(1.002-4.564)$ & 0.533 & 0.309 & 1.705 (0.609-4.768) \\
\hline lleocecectomy & 152 & 0 & - & & 0 & - & \\
\hline Indication of surgery & & & & & & & \\
\hline Medical intractability & 117 & -1.834 & $<0.001$ & $0.160(0.069-0.368)$ & -0.864 & 0.086 & $0.421(0.157-1.130)$ \\
\hline Intra-abdominal abscess & 162 & -0.004 & 0.986 & $0.996(0.616-1.610)$ & 0.873 & 0.028 & $2.393(1.098-5.216)$ \\
\hline Enterocutaneous fistula & 102 & -1.003 & 0.003 & 0.367 (0.187-0.719) & -0.304 & 0.543 & $0.738(0.277-1.965)$ \\
\hline Massive bleeding & 8 & 0.410 & 0.585 & $1.506(0.346-6.556)$ & 1.112 & 0.285 & 3.041 (0.395-23.386) \\
\hline Others & 74 & 0.248 & 0.410 & $1.281(0.711-2.307)$ & 1.206 & 0.011 & $3.342(1.317-8.480)$ \\
\hline Intestinal obstruction & 165 & 0 & - & & 0 & - & \\
\hline Time interval & & & & & & & \\
\hline Diagnosis after surgery & 55 & 1.359 & 0.000 & 3.893 (2.157-7.024) & 1.608 & $<0.001$ & 4.994 (2.123-11.745) \\
\hline Within 7 days & 144 & 0.480 & 0.039 & $1.615(1.026-2.544)$ & 0.850 & 0.019 & $2.339(1.147-4.771)$ \\
\hline Between 7 and 30 days & 32 & 0.603 & 0.146 & $1.828(0.811-4.120)$ & 0.321 & 0.655 & $1.378(0.337-5.636)$ \\
\hline Over 30 days & 397 & 0 & - & & 0 & - & \\
\hline
\end{tabular}

OR, odds ratio; $\mathrm{Cl}$, confidence interval; IPAA, ileal pouch anal anastomosis. 
not resected in that procedure, an increased reoperation rate was inevitable. However, contrary to other reports, the strictureplasty was not associated with repeated abdominal surgery reports [2629]. Unlike other reports [30-32], in the present study, the segmental colon resection was not a risk factor for repeated abdominal surgery in $\mathrm{CD}$ patients.

Emergency surgery and delayed diagnosis of $\mathrm{CD}$ after surgery could increase the risk for repeated abdominal surgery in $\mathrm{CD}$ patients. Hellberg et al. [33] demonstrated that no difference in recurrence existed between emergency and elective surgery. A limited resection could not be performed under an emergency situation because determining the extent of resection during emergency surgery was difficult. Understandably, a repeated abdominal surgery could be necessary. Similarly, in the presence of an intra-abdominal abscess, surgeons usually tend to perform fewer surgeries. Therefore, the probability of recurrence might be higher after the first abdominal surgery if the indication for the first operation had been an intra-abdominal abscess.

The present study had several limitations. First, some data were missing because of the retrospective collection technique, which could affect the results. Second, the efficacy of the medical treatment after surgery was not analyzed. Medical treatment, such as the use of immunomodulators or anti-tumor necrosis factor- $\alpha$, after abdominal surgery for $\mathrm{CD}$ could decrease the recurrence rate and affect the results of the present study.

In conclusion, young age (under 16 years of age), stricturing behavior, intra-abdominal abscess, emergency surgery, and delayed diagnosis after surgery may be risk factors for repeated abdominal surgery in Korean patients with CD.

\section{CONFLICT OF INTEREST}

No potential conflict of interest relevant to this article was reported.

\section{ACKNOWLEDGMENTS}

The authors thank members of the Korean IBD study group for considerable help in data acquisition.

\section{REFERENCES}

1. Wolff BG. Factors determining recurrence following surgery for Crohn's disease. World J Surg 1998;22:364-9.

2. Heimann TM, Greenstein AJ, Lewis B, Kaufman D, Heimann DM, Aufses AH Jr. Comparison of primary and reoperative surgery in patients with Crohns disease. Ann Surg 1998;227:492-5.

3. Goldberg PA, Wright JP, Gerber M, Claassen R. Incidence of surgical resection for Crohn's disease. Dis Colon Rectum 1993;36: 736-9.

4. Michelassi F, Balestracci T, Chappell R, Block GE. Primary and recurrent Crohn's disease: experience with 1379 patients. Ann Surg 1991;214:230-8.
5. Raab Y, Bergstrom R, Ejerblad S, Graf W, Pahlman L. Factors influencing recurrence in Crohn's disease: an analysis of a consecutive series of 353 patients treated with primary surgery. Dis Colon Rectum 1996;39:918-25.

6. Anseline PF, Wlodarczyk J, Murugasu R. Presence of granulomas is associated with recurrence after surgery for Crohn's disease: experience of a surgical unit. Br J Surg 1997;84:78-82.

7. Cottone M, Rosselli M, Orlando A, Oliva L, Puleo A, Cappello M, et al. Smoking habits and recurrence in Crohn's disease. Gastroenterology 1994;106:643-8.

8. Cunningham MF, Docherty NG, Coffey JC, Burke JP, O'Connell PR. Postsurgical recurrence of ileal Crohn's disease: an update on risk factors and intervention points to a central role for impaired host-microflora homeostasis. World J Surg 2010;34:1615-26.

9. Stange EF, Travis SP, Vermeire S, Beglinger C, Kupcinkas L, Geboes $\mathrm{K}$, et al. European evidence based consensus on the diagnosis and management of Crohn's disease: definitions and diagnosis. Gut 2006;55 Suppl 1:11-15.

10. Thia KT, Luman W, Jin OC. Crohn's disease runs a more aggressive course in young Asian patients. Inflamm Bowel Dis 2006;12: 57-61.

11. Satsangi J, Silverberg MS, Vermeire S, Colombel JF. The Montreal classification of inflammatory bowel disease: controversies, consensus, and implications. Gut 2006;55:749-53.

12. Brant SR, Panhuysen CI, Bailey-Wilson JE, Rohal PM, Lee S, Mann J, et al. Linkage heterogeneity for the IBD1 locus in Crohn's disease pedigrees by disease onset and severity. Gastroenterology 2000;119:1483-90.

13. Rioux JD, Silverberg MS, Daly MJ, Steinhart AH, McLeod RS, Griffiths AM, et al. Genomewide search in Canadian families with inflammatory bowel disease reveals two novel susceptibility loci. Am J Hum Genet 2000;66:1863-70.

14. Russell RK, Drummond HE, Nimmo EE, Anderson N, Smith L, Wilson DC, et al. Genotype-phenotype analysis in childhood-onset Crohn's disease: NOD2/CARD15 variants consistently predict phenotypic characteristics of severe disease. Inflamm Bowel Dis 2005; 11:955-64.

15. Vasiliauskas EA, Kam LY, Karp LC, Gaiennie J, Yang H, Targan SR, et al. Marker antibody expression stratifies Crohn's disease into immunologically homogeneous subgroups with distinct clinical characteristics. Gut 2000;47:487-96.

16. Polito JM 2nd, Childs B, Mellits ED, Tokayer AZ, Harris ML, Bayless TM. Crohn's disease: influence of age at diagnosis on site and clinical type of disease. Gastroenterology 1996;111:580-6.

17. Lashner BA, Evans AA, Kirsner JB, Hanauer SB. Prevalence and incidence of inflammatory bowel disease in family members. Gastroenterology 1986;91:1396-400.

18. Simillis C, Yamamoto T, Reese GE, Umegae S, Matsumoto K, Darzi $\mathrm{AW}$, et al. A meta-analysis comparing incidence of recurrence and indication for reoperation after surgery for perforating versus nonperforating Crohn's disease. Am J Gastroenterol 2008;103:196-205.

19. Sachar DB, Lemmer E, Ibrahim C, Edden Y, Ullman T, Ciardulo J, 
et al. Recurrence patterns after first resection for stricturing or penetrating Crohn's disease. Inflamm Bowel Dis 2009;15:1071-5.

20. Mirow L, Hauenschild L, Hildebrand P, Kleemann M, Keller R, Franke C, et al. Recurrence of Crohn's disease after surgery: causes and risks. Zentralbl Chir 2008;133:182-7.

21. Khoury W, Strong SA, Fazio VW, Kiran RP. Factors associated with operative recurrence early after resection for Crohn's disease. J Gastrointest Surg 2011;15:1354-60.

22. Farmer RG, Hawk WA, Turnbull RB Jr. Clinical patterns in Crohn's disease: a statistical study of 615 cases. Gastroenterology 1975;68(4 Pt 1):627-35.

23. Farmer RG, Whelan G, Fazio VW. Long-term follow-up of patients with Crohn's disease. Relationship between the clinical pattern and prognosis. Gastroenterology 1985;88:1818-25.

24. Bernell O, Lapidus A, Hellers G. Risk factors for surgery and postoperative recurrence in Crohn's disease. Ann Surg 2000;231:38-45.

25. Louis E, Collard A, Oger AF, Degroote E, Aboul Nasr El Yafi FA, Belaiche J. Behaviour of Crohn's disease according to the Vienna classification: changing pattern over the course of the disease. Gut 2001;49:777-82.

26. Shatari T, Clark MA, Yamamoto T, Menon A, Keh C, AlexanderWilliams J, et al. Long strictureplasty is as safe and effective as short strictureplasty in small-bowel Crohn's disease. Colorectal Dis 2004;6:438-41.

27. Yamamoto T, Allan RN, Keighley MR. Strategy for surgical management of ileocolonic anastomotic recurrence in Crohn's disease. World J Surg 1999;23:1055-60.

28. Gardiner KR, Kettlewell MG, Mortensen NJ. Intestinal haemorrhage after strictureplasty for Crohn's disease. Int J Colorectal Dis 1996;11:180-2.

29. Ozuner G, Fazio VW. Management of gastrointestinal bleeding after strictureplasty for Crohn's disease. Dis Colon Rectum 1995; 38:297-300.

30. Goligher JC. The long-term results of excisional surgery for primary and recurrent Crohn's disease of the large intestine. Dis Colon Rectum 1985;28:51-5.

31. Andrews HA, Lewis P, Allan RN. Prognosis after surgery for colonic Crohn's disease. Br J Surg 1989;76:1184-90.

32. Longo WE, Ballantyne GH, Cahow CE. Treatment of Crohn's colitis: segmental or total colectomy? Arch Surg 1988;123:588-90.

33. Hellberg R, Hulten L, Rosengren C, Ahren C. The recurrence rate after primary excisional surgery for Crohn's disease. Acta Chir Scand 1980;146:435-43. 